\title{
Vitamin B and Vitamin C Affect DNA Methylation and Amino Acid Metabolism in Mycobacterium bovis BCG
}

\begin{abstract}
Ningning Song ${ }^{1}$, Yongqiang Zhu ${ }^{2}$, Yingying Cui ${ }^{1}$, Mingyue Lv ${ }^{1}$, Yiyi Tang ${ }^{1}$, Ziyin Cui ${ }^{1}$, Guanghui Dang ${ }^{1}$, Huajun Zheng ${ }^{2 *}$ and Siguo Liu' ${ }^{1 *}$
\end{abstract}

1 State Key Laboratory of Veterinary Biotechnology, Harbin Veterinary Research Institute, Chinese Academy of Agricultural Sciences, Harbin, China, ${ }^{2}$ Shanghai-MOST Key Laboratory of Health and Disease Genomics, Chinese National Human Genome Center at Shanghai, Shanghai, China

Vitamins are essential nutrients and key cofactors of enzymes that regulate cellular metabolism, and also activate the immune system. Recent studies have shown that vitamin $\mathrm{B} 1\left(\mathrm{~V}_{\mathrm{B} 1}\right)$ and vitamin $\mathrm{C}(\mathrm{Vc})$ can inhibit Mycobacterium tuberculosis growth, but the precise mechanism is still not well understood. In the present study, we have used RNA-sequencing (RNA-seq), liquid chromatography coupled to mass spectrometry (LCMS) and single-molecule real-time (SMRT) sequencing to analyze the transcriptional, metabolic and methylation profiles of Mycobacterium bovis BCG when treated with $V_{\mathrm{B} 1}$ and $V_{c}$. Our results show that, after vitamin treatment, variant metabolites were mainly clustered in pathways related to amino acid metabolism. Treatment with both vitamins significantly up-regulated the gene encoding cysteine synthase A. Additionally, only BCG that was treated with $\mathrm{V}_{\mathrm{C}}$ showed $\mathrm{m} 4 \mathrm{c}$ modifications. Genes harboring this methylation were up-regulated, suggesting that $\mathrm{m} 4 \mathrm{c}$ methylation can promote gene transcription to some extent. Overall, this study contributes to the understanding of the effects of $V_{B 1}$ and $V_{C}$, and suggests that these vitamins constitute potential anti-tuberculosis drugs.

Keywords: vitamin, methylation, amino acid, Mycobacterium, cysterine synthase A

\section{INTRODUCTION}

Mycobacterium tuberculosis (Mtb) is a well-known intracellular pathogen which causes almost nine million cases of tuberculosis every year and latently infects up to a third of the world population (World Health Organization [WHO], 2019). Mtb is able to persist in the host for decades without causing clinical symptoms, and has evolved adaptation mechanisms to survive in the harsh environment of the host, such as hypoxia, nutrient deprivation or low $\mathrm{pH}$ (Betts et al., 2002; Fisher et al., 2002; Schnappinger et al., 2003). This adaptation is possible by regulation of gene expression, which in turn can be controlled by DNA methylation (Shell et al., 2013).

DNA methylation has been known since the 1950s (Luria and Human, 1952). In prokaryotes, it represents a primitive defense mechanism against phages and viruses, known as the RestrictionModification (RM) system. Although adenine is the most important methylation target, e.g., $N^{6}$ methyl-adenosine $(\mathrm{m} 6 \mathrm{~A})$, there are other two types of methylation. These are found in cytosine and depend on the modification site: $\mathrm{m} 4 \mathrm{C}\left(N^{4}\right.$-methyl-cytosine) and $\mathrm{m} 5 \mathrm{C}\left(C^{5}\right.$-methyl-cytosine) 
(Murphy et al., 2013). In general, m6A has been used as the main signal for epigenetic regulation in bacteria, $\mathrm{m} 5 \mathrm{C}$ has been mainly described in mammals and plant studies (Kim et al., 2009), whereas m4C is mainly present in bacteria (Kumar et al., 2018).

DNA methylation plays an important role in the epigenetic regulation of eukaryotes via gene expression modulation (Moore et al., 2013). Indeed, methylation of promoter and gene body can either silence or promote expression, respectively (Yang et al., 2014). In bacteria, DNA methylation may also play regulatory roles in the control of DNA replication or transcription (Reisenauer et al., 1999), and this may contribute to environmental adaptation and metabolic activity (Blow et al., 2016).

Single-molecule real-time (SMRT) sequencing (Pacific Biosciences) is a recently developed DNA sequencing method where kinetic data can also be used to distinguish base modifications, e.g., methylation, at the single nucleotide level (Flusberg et al., 2010). Several bacterial methylomes have been determined using SMRT sequencing technology (Fang et al., 2012; Krebes et al., 2014; Zhu et al., 2016). Specifically, a methylome analysis of $M$. tuberculosis complex (MTBC) was reported by Zhu et al. (2016).

Vitamins are organic compounds that cannot be produced by the host organism. Even when they are produced, concentrations are low and external supplementation from the diet or from commensal bacteria is required. Vitamins have been found to regulate immunity, and a number of studies have reported the effect of vitamins as adjunct to treat tuberculosis (Parida et al., 2015; He et al., 2018). For example, vitamins A, C and $\mathrm{D}$ have been used as adjunct to complement anti-tuberculosis drugs (Dini and Bianchi, 2012; Vilcheze et al., 2013; Syal et al., 2015). The active form of thiamin (Vitamin B1, $\mathrm{V}_{\mathrm{B} 1}$ ), thiamin diphosphate (ThDP) (Begley et al., 1999; Settembre et al., 2003; Pohl et al., 2004), is an essential cofactor in all organisms, taking an important role in energy metabolism and degradation of sugars. In addition, $\mathrm{V}_{\mathrm{B} 1}$ plays an important role in the activation of the immune system, nerve tissue repair, neuronal communication and cell-membrane dynamics (Gibson and Blass, 2007; Manzetti et al., 2014). Recent studies have shown the effects of $\mathrm{V}_{\mathrm{B} 1}$ both in vitro and in vivo; $\mathrm{V}_{\mathrm{B} 1}$ inhibits in vitro growth of BCG with an MIC of $8 \mathrm{mM}$, whereas it limits $\mathrm{Mtb}$ in vivo growth by regulating innate immunity in a peroxisome proliferatoractivated receptor $\gamma$-dependent manner ( $\mathrm{Hu}$ et al., 2018; Song et al., 2019). $\mathrm{V}_{\mathrm{C}}$ also can hamper the growth of Mtb by $\mathrm{a}$ mechanism that involves the reduction of ferric to ferrous ion and subsequent production of reactive oxygen species (i.e., hydrogen peroxide, superoxide and hydroxyl radicals) through HarberWeiss cycle and Fenton reactions (Vilcheze et al., 2013). BCG is also sensitive to Vc, with an MIC is $0.8 \mathrm{mM}$ (Pei et al., 2019).

Microbial metabolomics constitutes an integrated component of systems biology. By studying the complete set of metabolites within a microorganism and monitoring the global outcome of interactions between its development processes and the environment, metabolomics can potentially provide a more accurate snap shot of the actual physiological state of the cell. Furthermore, when these data are interpreted in combination with genomics, proteomics and transcriptomics data and so on, using what is termed a systems biology approach, a more holistic understanding of these systems can be achieved. Up to now, the metabolomics has contributed to characterize Mtb in terms of metabolism, growth and replication, pathogenicity, and drug resistance, from the perspective of systems biology (Swanepoel and Loots, 2014). For example, Meissner-Roloff compared the metabolomes of a hypo- and hyper-virulent Beijing Mtb strain and subsequently identified a reduction in various metabolite markers in the relatively hyper-virulent strain (Meissner-Roloff et al., 2012). Loots used metabolomics approach to identify potentially new metabolic pathways and metabolite markers to explain many of the phenotypical characteristics associated with a katG mutation and the resulting isoniazid-resistance in Mtb (Loots du, 2014). Additionally, metabolomics was to identify individual metabolites or metabolite profiles that could be used as biomarkers of early MAP (Mycobacterium avium subsp. Paratuberculosis) infection in ruminants (De Buck et al., 2014).

However, despite transcriptomics and proteomics efforts have been studied (Shiloh et al., 2008; Mishra and Sarkar, 2015; Batra et al., 2017; Martini et al., 2019), the effect of vitamin treatment on Mtb metabolomics and gene methylation remains poorly understood. DNA methylation and transcriptional regulation are tightly related and play an important role in the epigenetics of living organisms, whereas vitamins have an anti-tuberculosis effect. These prompted us to study the methylome, transcriptome and changes in metabolism of Mycobacterium bovis BCG after $\mathrm{V}_{\mathrm{B} 1}$ and $\mathrm{V}_{\mathrm{C}}$ stimulation.

\section{MATERIALS AND METHODS}

\section{Bacterial Strains and Culture Conditions}

Mycobacterium bovis BCG str. Tokyo 172 strain was grown in Middlebrook 7H9 medium Becton Dickinson, supplemented with $0.05 \%$ Tween-80 (v/v), 10\% ADC (Albumin-DextroseCatalase, $\mathrm{BD})$ and $0.2 \%(\mathrm{v} / \mathrm{v})$ glycerol. When $\mathrm{OD}_{600 \mathrm{~nm}}$ reached $0.3, \mathrm{~V}_{\mathrm{B} 1}$ and $\mathrm{V}_{\mathrm{C}}$ were added with final concentrations of 8 and $5 \mathrm{mM}$, respectively. This was followed by incubation at $37^{\circ} \mathrm{C}$ for $48 \mathrm{~h}$. At least three replicates were prepared for each condition. Different concentrations $(0,1,2$, and $4 \mathrm{mM})$ of cysteine were used to test the effect for BCG growth.

\section{Genomic DNA Extraction and SMRT Sequencing}

BCG pellets were collected by centrifugation and suspended with lysis buffer (20 mM Tris.Cl, pH 8.0; 2 mM sodium EDTA; 1.2\% Triton $^{\circledR} \mathrm{X}-100,20 \mathrm{mg} / \mathrm{mL}$ lysozyme). These samples were then sonicated for $5 \mathrm{~min}$ and incubated at $37^{\circ} \mathrm{C}$ for $1 \mathrm{~h}$. RNase was added to the sonicated samples and incubated for $5 \mathrm{~min}$ at room temperature, followed by protease $\mathrm{K}$ addition, according to manufacturer instructions (TIANamp Bacteria DNA Kit protocol, Tiangen Biotech, Beijing, China). The concentration of DNA samples was determined using a NanoDrop ND-2000 spectrophotometer. The extracted genomic DNA from BCG was sequenced using the Pacific Biosciences RSII DNA sequencing system (Pacific Biosciences, Menlo Park, CA, United States). A 10-kb SMRTbell library was prepared from sheared genomic 
DNA ( $>5 \mathrm{~g}$ ) using a 10-kb template library preparation workflow, according to the manufacturer. One SMRT cell was used for each sequencing.

\section{Bioinformatic Analyses of SMRT Sequencing Data}

De novo assembly of the insert reads was performed with the Hierarchical Genome Assembly Process (HGAP.3) algorithm in the SMRT Portal (version 2.2.0). Circularization was achieved by manual comparison and removal of an overlap region. The final genome was confirmed by remapping of sequence data. Promoter regions were analyzed using the Neural Network Promoter Prediction tool ${ }^{1}$ and PePPER ${ }^{2}$.

Genome-wide detection of base modification and sequence motifs was performed using the standard settings (QV of modified motifs are more than 30) in the protocol 'RS Modification and Motif Analysis.1' included in the SMRT Portal version 2.2.0. 'Motif score' $=$ (number of detections matching motif)/(number of genome sites matching motif) $\times$ (sum of $\log -\mathrm{p}$ value of detections matching motif) = (fraction methylated $) \times$ (sum of log-p values of matches). The SMRT Portal searches (close to maximize) through of all possible motifs, progressively testing longer motifs using a branch-and-bound search. The minimal term 'motif score' and 'fraction methylated' parameters were 40 and less than 1 , respectively.

\section{LC-MS Based Metabolomic Analysis}

The BCG strains cultured with 7H9 medium in the absence and/or presence of $\mathrm{V}_{\mathrm{B} 1}$ and $\mathrm{V}_{\mathrm{C}}$ were collected after $48 \mathrm{~h}$ incubation at $37^{\circ} \mathrm{C}$. The $60 \mathrm{mg}$ pellets were collected by centrifugation and the supernatant were removed, the metabolites are measured by LC-MS as described (Song et al., 2019). Collected bacteria were ground and dissolved in an aqueous methanol solution (water:methanol, 1:1, v/v) at $4^{\circ} \mathrm{C}$. After membrane filtration $(0.22 \mu \mathrm{m})$, samples were used for LC-MS detection. Separation was achieved in a Shimadzu LC-30A system equipped with an ACQUITY UPLC HSS T3 $(150 \times 2.1 \mathrm{~mm}, 1.8 \mu \mathrm{m}$, Waters $)$ column maintained at $40^{\circ} \mathrm{C}$. The temperature of the autosampler was $4^{\circ} \mathrm{C}$. Gradient elution of analytes was carried out with $0.1 \%$ formic acid in water (solvent A) and acetonitrile (solvent B) at a flow rate of $0.3 \mathrm{~mL} / \mathrm{min}$. After equilibration, $5 \mu \mathrm{L}$ of each sample were injected. Solvent B was increased linearly as follows: $2 \%(0-0.5 \mathrm{~min})$, from 2 to $50 \%$ (0.5-9 $\mathrm{min})$, from 50 to $98 \%$ (9-12 $\mathrm{min}), 98 \%$ (12-13 $\mathrm{min})$, from 98 to $2 \%$ (13-14 $\mathrm{min})$, and $2 \%(14-15 \mathrm{~min})$.

The ESI-MS experiments were executed on the AB 5600+ mass spectrometer with the spray voltage of $5.50 \mathrm{kV}$ and $-4.50 \mathrm{kV}$ in positive and negative modes, respectively. Gas1 and gas2 were both set at 50 psi and curtain gas was 35 psi. The source temperature was $500^{\circ} \mathrm{C}$. The mass analyzer scanned over a $\mathrm{m} / \mathrm{z}$ range of 100-1,500 for a full scan at a collision energy of $45 \mathrm{eV}$ with dynamic exclusion.

\footnotetext{
${ }^{1}$ http://www.fruitfly.org/seq_tools/promoter.html

${ }^{2} \mathrm{http} / / /$ genome2d.molgenrug.nl/g2d_pepper_promoters.php
}

\section{Determination of Amino Acids}

The amino acids of samples treated with $V_{B 1}$ and $V_{C}$ were detected by HR-UPLC-MS (high resolution ultra-performance liquid chromatography-mass spectrometry) as described (Song et al., 2019). Briefly, an equimolar standard mixture of 20 amino acids (i.e., glycine, L-sarcosine, L-alanine, L-valine, L-proline, Lthreonine, L-isoleucine, L-leucine, L-ornithine, L-methionine, Lhistidine, L-phenylalanine, L-arginine, L-tyrosine, L-aspartic acid, L-tryptophan, 4-aminobutyric acid, L-serine, L-lysine, L-glutamic acid) was prepared with concentrations $0.2,0.5,1,2,5,10,20$, and $50 \mu \mathrm{g} / \mathrm{mL}$.

Pellets of bacteria (100 mg) were ground in liquid nitrogen, and amino acids were extracted with $1 \mathrm{~mL} \mathrm{HCl}$ overnight. The supernatant was collected by centrifugation at 12,000 rpm for $5 \mathrm{~min}$. After addition of $100 \mu \mathrm{L}$ of an internal standard, isotope-labeled amino acid (Alanine - d4), the sample was dried under a moderate nitrogen gas stream. A volume of $60 \mu \mathrm{L}$ of derivatization reagent [hydrochloric acid/n-butyl alcohol (1:3, $\mathrm{v} / \mathrm{v})$ ] was added into the mixture and incubated for $15 \mathrm{~min}$ at $65^{\circ} \mathrm{C}$, and the sample was analyzed by UPLC-MS.

Chromatographic separation was achieved with an ACQUITY UPLC system equipped with a $1.7 \mu \mathrm{m}$ C18 column (ACQUITY UPLC BEH, $2.1 \times 100 \mathrm{~mm}$, Waters) at $40^{\circ} \mathrm{C}$. Gradient elution of the analytes was implemented with solvent $\mathrm{A}(0.1 \%$ formic acid and $0.1 \%$ heptafluorobutyric acid in acetonitrile) and solvent $\mathrm{B}$ $(0.1 \%$ formic acid in water), at a flow rate of $0.25 \mathrm{~mL} / \mathrm{min}$. Five $\mu \mathrm{L}$ of sample were injected following equilibration. An increasing linear gradient of solvent A (v/v) was used as follows: $5 \%$ A (0$1.5 \mathrm{~min}) ; 5$ to $20 \% \mathrm{~A}(1.5-2 \mathrm{~min}) ; 20$ to $30 \% \mathrm{~A}(2-7 \mathrm{~min}) ; 30$ to $98 \% \mathrm{~A}(7-8.5 \mathrm{~min})$; $98 \% \mathrm{~A}(8.5-10.5 \mathrm{~min})$; 98 to $5 \% \mathrm{~A}(10.5-$ $11 \mathrm{~min})$ and $5 \% \mathrm{~A}(11-12.5 \mathrm{~min})$.

The ESI source was applied in positive mode by multiple reaction monitoring (MRM). The ion source capillary voltage and cone voltage were set as 3,200 and $20 \mathrm{~V}$, respectively, and the desolvation temperature was set at $380^{\circ} \mathrm{C}$.

\section{RNA Extraction and Library Construction}

Since methylation and transcriptomics are both ways of studying epigenetics and they have the close relationship, to further investigate how $\mathrm{V}_{\mathrm{B} 1}$ and $\mathrm{V}_{\mathrm{C}}$ treatment affect BCG growth, RNA-seq was used to compare the transcriptome of the three replicates of each $B C G$ sample $\left(\mathrm{V}_{\mathrm{B} 1}\right.$-treated, $\mathrm{V}_{\mathrm{C}}$-treated and control). RNA-seq was performed as described (Song et al., 2019) on three replicates of bacteria treated with $V_{B 1}$ and $V_{C}$. Cell pellets were lysed and homogenized by high-speed agitation in a bead mill in presence of glass beads and lysis buffer. Total RNA was extracted using RNeasy Mini Kit (Qiagen) according to the instructions with one on-column DNase I treatment (Qiagen) at $37^{\circ} \mathrm{C}$ for $30 \mathrm{~min}$, in order to remove any contaminating genomic DNA. DNase I was removed with RNeasy mini kit, according to the clean-up procedure (Song et al., 2019). The RNA integrity number (RIN) was used to inspect RNA integrity by an Agilent Bioanalyzer 2100 (Agilent Technologies, Santa Clara, CA, United States). The concentration of RNA samples was determined with a NanoDrop ND-2000 spectrophotometer. The strand-specific 
library was constructed using TruSeq ${ }^{\circledR}$ Stranded Total RNA Sample Preparation kit (Illumina, United States). The ribosomal RNA was removed and the RNA fragments were cleaved, whereas the first and second strand CDNA were synthesized. A single 'A' nucleotide was added to the 3 ' ends of the blunt DNA fragments with repaired ends, and subsequently connected with adapters. The purified libraries were quantified using Qubit $^{\circledR}$ 2.0 Fluorometer (Life Technologies, United States) and validated by Agilent 2100 bioanalyzer (Agilent Technologies, United States), in order to measure concentration and confirm insert size. The cluster was generated by cBot, and RNA sequencing was performed using a 150 bp pair-end strategy with the Illumina Hiseq X10 platform (Illumina, United States) to generate three billion bases per sample. Thereafter, raw data was acquired, followed by pretreatment using Septk1. The read length was > $90 \mathrm{nt}$. The clean reads were mapped to the Mycobacterium bovis BCG str. Tokyo 172 genome using Bowtie2 (Langmead and Salzberg, 2012). Differential expression analysis was performed using edgeR package (Robinson et al., 2010). Differentially expressed genes were defined as experiencing more than a 2 -fold change and a FDR (false discovery rate) of less than 0.05 .

Enrichment of KEGG pathways for a given gene list was calculated using a classical hypergeometric distribution statistical comparison of a query gene list against a reference gene list. The calculated $p$-value was FDR-corrected, and the corrected $p$-value $<0.05$ was used as a threshold. KEGG pathways fulfilling this condition were defined as significantly enriched in regulated genes.

The raw data was deposited in the GEO repository, under accession numbers GSE114949 (V $\mathrm{V}_{\mathrm{B} 1}$-treated) and GSE141513 ( $\mathrm{V}_{\mathrm{C}}$-treated).

\section{Statistical Analysis}

The experiments were performed at least in biological triplicate and the results are presented as the mean \pm standard deviation (SD). Values were considered to be statistically significant when $P$-value was $<0.05$ and the statistical significance of the observed differences was assessed with one way analysis of variance (oneway ANOVA).

\section{RESULTS}

\section{DNA Methylome Analysis}

Since the CFU counting of BCG is similar after $\mathrm{V}_{\mathrm{B} 1}(8 \mathrm{mM})$ and $V_{C}(5 \mathrm{mM})$ treatment for $48 \mathrm{~h}$ and the differentiation continues comparing with the control group (Figure 1), all the omics studies were performed with final concentration of $8 \mathrm{mM}$ for $\mathrm{V}_{\mathrm{B} 1}$ and $5 \mathrm{mM}$ for $\mathrm{Vc}$. SMRT sequencing was used to determine the genome-wide distribution of methylated bases in $\mathrm{V}_{\mathrm{C}}$-treated, $\mathrm{V}_{\mathrm{B} 1}$-treated and control BCG. The average sequencing coverage was 363-531X (Supplementary Table 1). Analysis of the SMRT-sequenced data detected $N^{6}$-methyladenine (m6A) in the three samples, whereas $\mathrm{m} 4 \mathrm{C}$ sites, 5,317 , were only detected in the Vc-treated BCG sample (Supplementary Table 2).

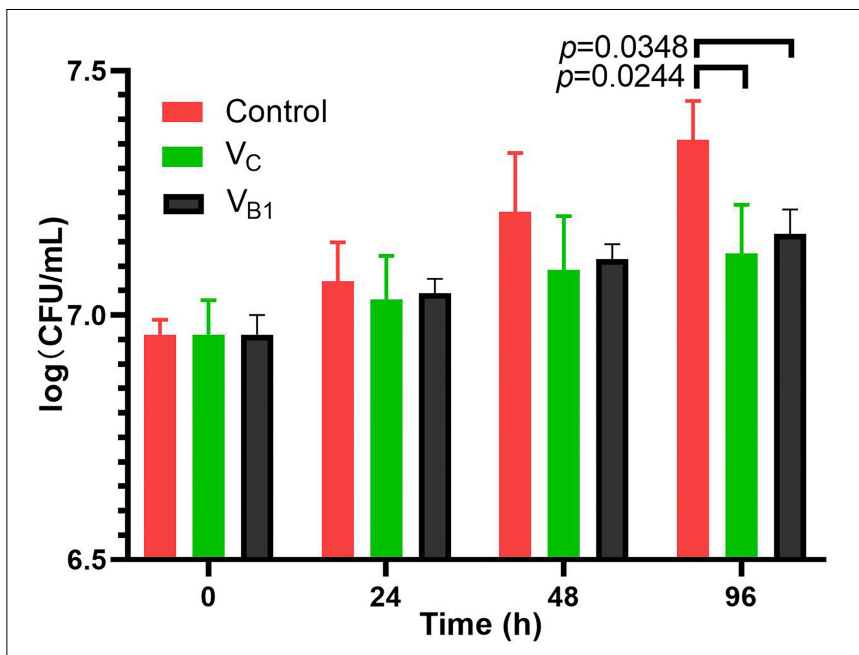

FIGURE 1 | CFU assays of BCG treated with $V_{B 1}(8 \mathrm{mM})$ and $V_{c}(5 \mathrm{mM})$.

\section{Distribution of m6A Loci}

In total, 5,191 m6A sites were detected in the three BCG samples and 4,641 of them $(89.4 \%)$ were common to all three, with 19 , 20 , and 11 unique sites in $\mathrm{V}_{\mathrm{B} 1}$ - treated, $\mathrm{V}_{\mathrm{C}}$-treated and control BCG samples, respectively (Supplementary Figure 1). Five m6A sequence motifs were detected (Supplementary Table 3). The CTCCAG/CTGGAG motif represented in approximately $74 \%$ of them $(1,931)$ and was distributed randomly across the genome. A total of 3,756 adenines in this motif (97.3\%) were methylated in the three BCG samples, suggesting that this motif has a protective role. A total of 1,784 protein coding sequences (CDS) were affected by m6A, accounting for $42.6 \%$ of BCG genes. Enrichment analysis revealed that important pathways involved in metabolism, cellular processes and environmental information processing were significantly affected by m6A (FDR $<0.05$, Supplementary Table 4). COG class enrichment analysis also revealed that m6A was present in genes participating in cell envelope biogenesis and outer membrane, also suggesting that the m6A modification has a protective role. In contrast, un-methylated genes (i.e., those that did not have $\mathrm{m} 6 \mathrm{~A}$ or $\mathrm{m} 4 \mathrm{C}$ modifications) were enriched in pathways Ribosome and Translation, Membrane transport, and Metabolism of cofactors and vitamins (Supplementary Table 5). COG class enrichment analysis also revealed abundant unmethylated genes with unknown biological function.

\section{Distribution of m4C Loci}

Surprisingly, m4C was observed only in samples treated with $\mathrm{V}_{\mathrm{C}}$, with 5,317 m4C sites in three motifs (Supplementary Table 3). 2,374 CDSs were affected by $\mathrm{m} 4 \mathrm{C}$, accounting for $56.7 \%$ of BCG genes. Among these, 1,221 CDSs were also methylated at adenine sites (i.e., $69.1 \%$ of the 1,767 m6A modified genes). Enrichment analysis revealed that $\mathrm{m} 4 \mathrm{C}$ modification mainly affected genes involved in amino acid metabolism, cell envelope biogenesis and outer membrane (FDR $<0.05$, Supplementary Table 6). This 
A

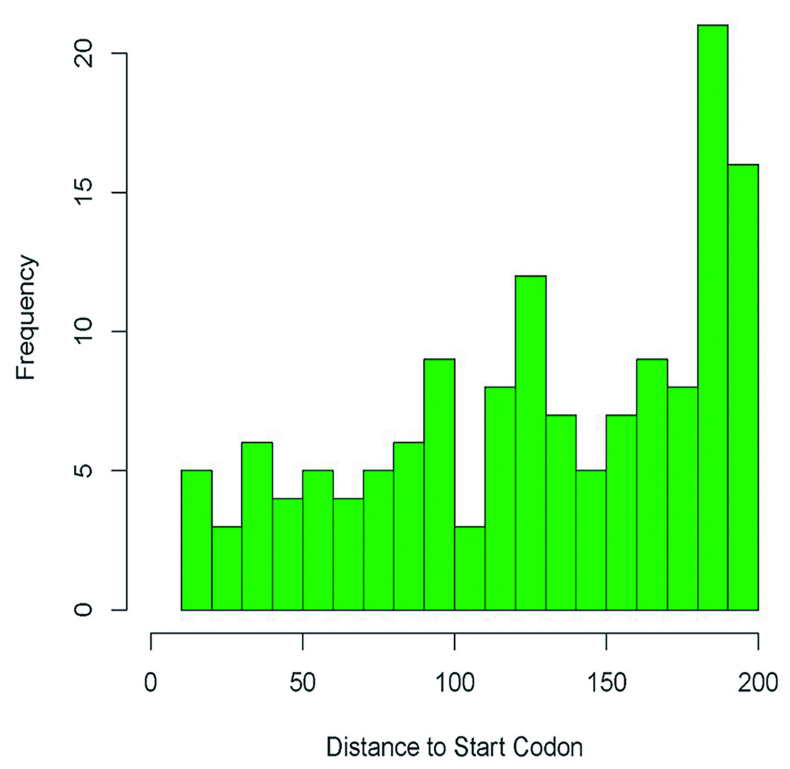

B

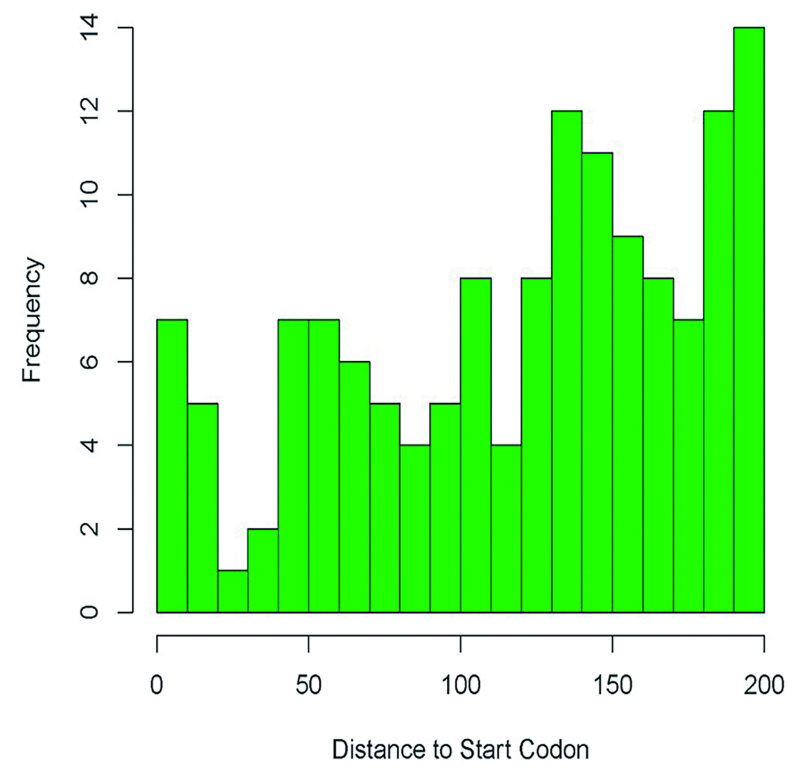

FIGURE 2 | Distances relative to the start codon in intergenic region of $m 6 A$ sites (A) and $m 4 C$ sites (B) basing on the methylation sites in $V_{B 1}$ and $V_{C}$ treated $B C G$ samples.

suggests that, since $\mathrm{V}_{\mathrm{C}}$ treatment hampers BCG growth, genes involved in cell envelope biogenesis become more protected.

\section{Presence of m6A and $\mathrm{m} 4 \mathrm{C}$ in Intergenic Regions (IGRs)}

In eukaryotes, promoter methylation has been suggested to inhibit gene expression. Our analysis discovered 4,781 m6A sites located in CDSs, and 410 (7.9\%) in IGRs. Since the promoter regions in bacteria are usually located within 100 bp upstream of the start codon (Heyden et al., 1975; Chen et al., 2010), we calculated the distance between the methylation sites and the downstream start codon. Only m6A modifications located within $200 \mathrm{bp}$ upstream of the start codon were assumed to affect genes. In this way, only 143 out of the $410 \mathrm{~m} 6 \mathrm{~A}$ sites in IGRs probably affected the promoters of 138 genes (Supplementary Table 12). In BCG treated with $\mathrm{V}_{\mathrm{C}}, 423 \mathrm{~m} 4 \mathrm{C}$ were located in IGRs, where 142 affected promoters of 140 genes (Supplementary Table 12). Further analysis revealed a relative enrichment of $\mathrm{m} 6 \mathrm{~A}$ at positions in the range -180 to $-200 \mathrm{bp}$ (Figure 2A) that was less evident for the $\mathrm{m} 4 \mathrm{C}$ sites (Figure 2B).

\section{The Transcriptome of BCG}

To investigate how $\mathrm{V}_{\mathrm{B} 1}$ and $\mathrm{V}_{\mathrm{C}}$ treatment affects BCG growth, RNA-seq was used to compare the transcriptome of the three replicates of each BCG sample $\left(\mathrm{V}_{\mathrm{B} 1}\right.$-treated, $\mathrm{V}_{\mathrm{C}}$-treated and control). The mean FPKM (Fragments Per Kilo bases per Million reads) was 274.4 for $\mathrm{V}_{\mathrm{B} 1}$-treated BCG (282.5 for control) and 289.4 for Vc-treated BCG (281.9 for control). A total of 260 genes were regulated in $\mathrm{V}_{\mathrm{B} 1}$-treated $\mathrm{BCG}$, and 278 in

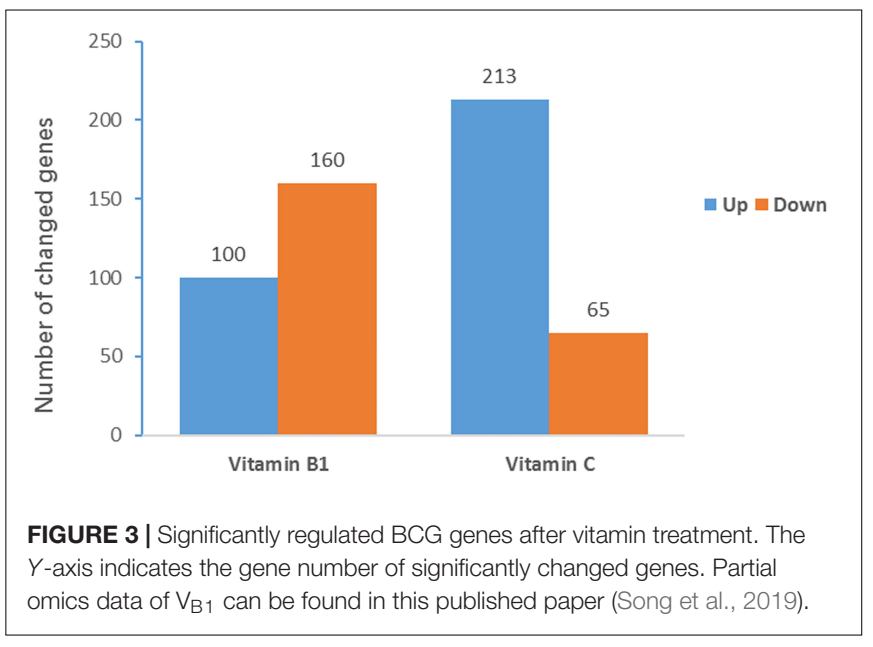

Vc-treated BCG (Figure 3). Of these, more down-regulated genes were found for $\mathrm{V}_{\mathrm{B} 1}$-treated $\mathrm{BCG}$, which were enriched in pathways like Nitrogen metabolism and Two-component system (Supplementary Table 7 ). In contrast, $\mathrm{V}_{\mathrm{C}}$-treated BCG showed more up-regulated genes involved in replication and repair. In the Vc-treated BCG samples, lower expression was found in genes involved in energy metabolism. In addition, we note that expression of genes involved in biosynthesis of siderophore group non-ribosomal peptides was inhibited by $\mathrm{V}_{\mathrm{B} 1}$, but stimulated by $\mathrm{V}_{\mathrm{C}}$ (Supplementary Table 7). The same pattern was observed for another six genes, with two of them (mycobactin polyketide synthetase gene $M b t B$ and $M b t C$ ) participating in this pathway. 


\section{DNA Methylation and RNA Expression}

To investigate the relationship between gene methylation and gene expression, we analyzed the methylation changes in significantly regulated genes. There were 19 unique m6A sites in $V_{B 1}$-treated $B C G$, but only one of them was located within the coding region of significantly down-regulated genes, away from the promoter region. For the 20 unique m6A sites in $\mathrm{V}_{\mathrm{C}}$-treated BCG, two were located in the promoter region of significantly up-regulated genes (Supplementary Table 11). In that sample, $\mathrm{m} 4 \mathrm{C}$ was found in the coding region of 31 down-regulated genes (47.7\%) and 138 up-regulated genes (64.8\%) (Supplementary Table 11), but it was observed in the promoter region only in 11 up-regulated genes (Supplementary Table 12). These results suggest that gene expression is not affected when methylation is in the coding region, but when $\mathrm{m} 4 \mathrm{C}$ is located in the promoter region it contributes to upregulate BCG gene expression. To validate this hypothesis, we compared the gene expression levels of methylated and non-methylated genes, based on their FPKM. Although no significant changes were observed for m6A-modified genes (Supplementary Figure 2), the expression levels of 65 genes harboring $\mathrm{m} 4 \mathrm{C}$ sites in the promoter region was significantly higher than in the control that had no $\mathrm{m} 4 \mathrm{C}$ sites (mean FPKM $=272.3$ and 222.9, respectively and $p<0.05$ ) (see Supplementary Figure 3).

\section{Metabolite Analysis}

Liquid chromatography-mass spectrometry (LC-MS) was used to analyze six bacterial sediments of each of the three BCG samples $\left(\mathrm{V}_{\mathrm{B} 1}\right.$-treated, $\mathrm{V}_{\mathrm{C}}$-treated and control). After $\mathrm{V}_{\mathrm{B} 1}$ or $\mathrm{V}_{\mathrm{C}}$ treatment, the number of differential metabolites was 428 and 3,208, respectively (Figure 4).

We identified 41 metabolites with significant variation, 10 in $\mathrm{V}_{\mathrm{B} 1}$-treated $\mathrm{BCG}$ and 21 in Vc-treated BCG (Figure 5). In $\mathrm{V}_{\mathrm{B} 1}$ treated $\mathrm{BCG}$ samples, the concentration of LysoPE[0:0/18:2(9Z,12Z)], PE[18:1(9Z)/0:0], 5-S-methyl5-thioadenosine and $S$-adenosylhomocysteine increased,

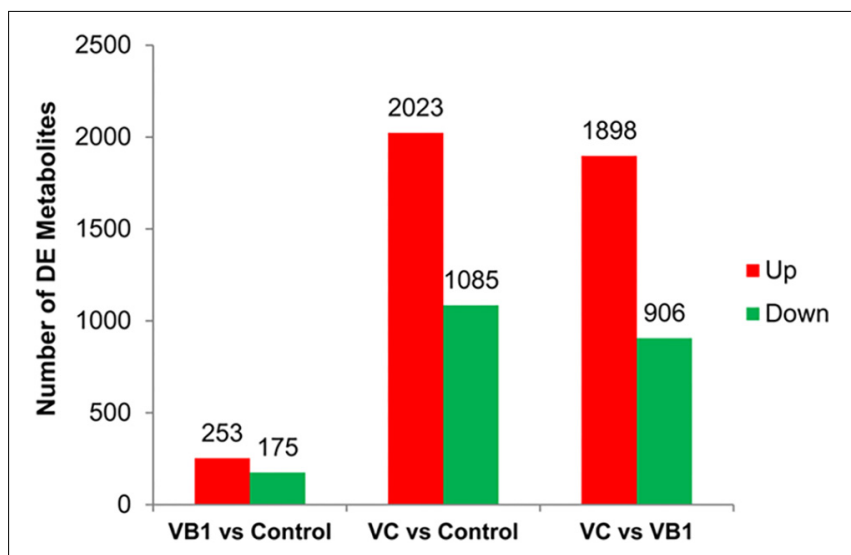

FIGURE 4 | The diagram for differential metabolites found in the three BCG samples examined. Partial omics data of $\mathrm{V}_{\mathrm{B} 1}$ can be found in this published paper (Song et al., 2019). but the concentration of Adenosine 5-phosphate disodium, L-Tryptophan, 4-nonylphenol, inosine, Geranylgeranyl PP and ADP decreased. In Vc treated BCG samples, the concentration of Nylidrin, 2-Phenylbutyrolactone, Oleamide, $S$-adenosylhomocysteine, diphenylamine, 5-S-methyl-5thioadenosine, 4-nitrophenol, adenosine, Nonanedioic acid and sebacic acid increased, in the contrast, the concentration of 12-OAHSA, ADP, L-tyrosine, 4-nonylphenol, L-Tryptophan, inosine, NAD, Adenosine 5-phosphate disodium, (+)-trans-C75, dodecanedioic acid and 9(S)-HPODE decreased (Figure 5). Enrichment analysis revealed that variant metabolites were mainly clustered in amino acid metabolism pathways (Supplementary Table 8). After $\mathrm{V}_{\mathrm{B} 1}$ treatment, variant metabolites were significantly enriched in cysteine and methionine metabolism (Supplementary Table 7).

\section{Metabolism of Amino Acids}

Since exposure to vitamins led to variant metabolites enrichment in amino acid metabolism pathways, we performed additional amino acids content analysis using six bacterial sediments of each of the three BCG samples $\left(\mathrm{V}_{\mathrm{B} 1}\right.$-treated, $\mathrm{V}_{\mathrm{C}}$-treated and control). Exposure to vitamins significantly reduced $\left(\mathrm{V}_{\mathrm{B} 1}\right)$ or increased $\left(\mathrm{V}_{\mathrm{C}}\right)$ amino acid content (Supplementary Table 9). The expression changes associated with amino acid metabolism were also analyzed, as described below.

\section{$\mathbf{V}_{\mathrm{B} 1}$ Addition}

After $V_{B 1}$ addition to $B C G$, a key enzyme involved in thiamine $\left(\mathrm{V}_{\mathrm{B} 1}\right)$ metabolism (hydroxymethylpyrimidine/ phosphomethylpyrimidine kinase [2.7.4.7]) was significantly down-regulated (Supplementary Figure 4), suggesting that $\mathrm{V}_{\mathrm{B} 1}$ addition reduced the requirement for de novo synthesis of thiamine. Another significantly down-regulated gene was chorismate mutase [5.4.99.5] (Supplementary Figure 5 and Supplementary Table 10), which catalyzes the transformation from chorismate to prephenate, the precursor of phenylalanine and tyrosine. This is consistent with the observed $80 \%$ reduction in Phe and Tyr after $V_{B 1}$ addition. This treatment also caused almost 50\% reduction in alanine, although the gene expression of alanine dehydrogenase [1.4.1.1] showed no significant down-regulation. Instead, the gene expression of the two alanine dehydrogenase genes (JTY_RS14370 and JTY_RS14375) increased slightly, which suggests that alanine reduction was caused by lower availability of pyruvate.

We then examined the pyruvate metabolism and glycolysis pathways. In the pyruvate metabolism pathway, no significant up-regulation was observed, indicating that the conversion of pyruvate to other metabolites did not increase. However, in the glycolysis pathway, a 51-fold reduced expression was observed for 6-phosphofructokinase 2 [2.7.1.11], an enzyme that converts fructose- $6 \mathrm{P}$ into fructose- $1,6 \mathrm{P} 2$, which may explain the $50 \%$ reduction in alanine after $\mathrm{V}_{\mathrm{B} 1}$ addition (Supplementary Figure 5). For histidine synthesis, although no significant gene expression change was observed, genes involved in five out of nine steps were down-regulated. Genes involved in the synthesis of other amino acids also showed the same pattern, where at 


\section{A}

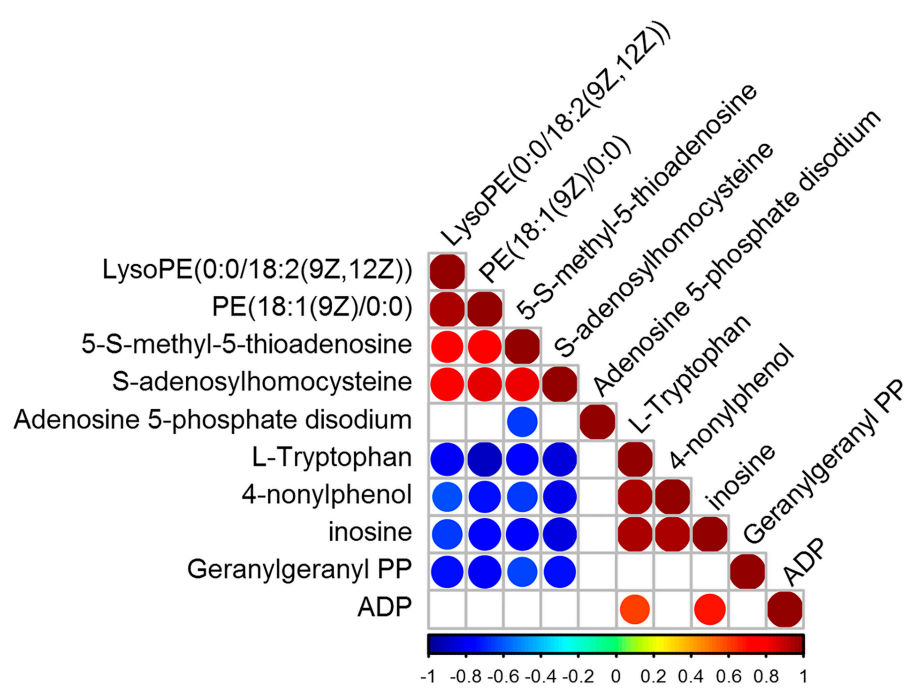

B

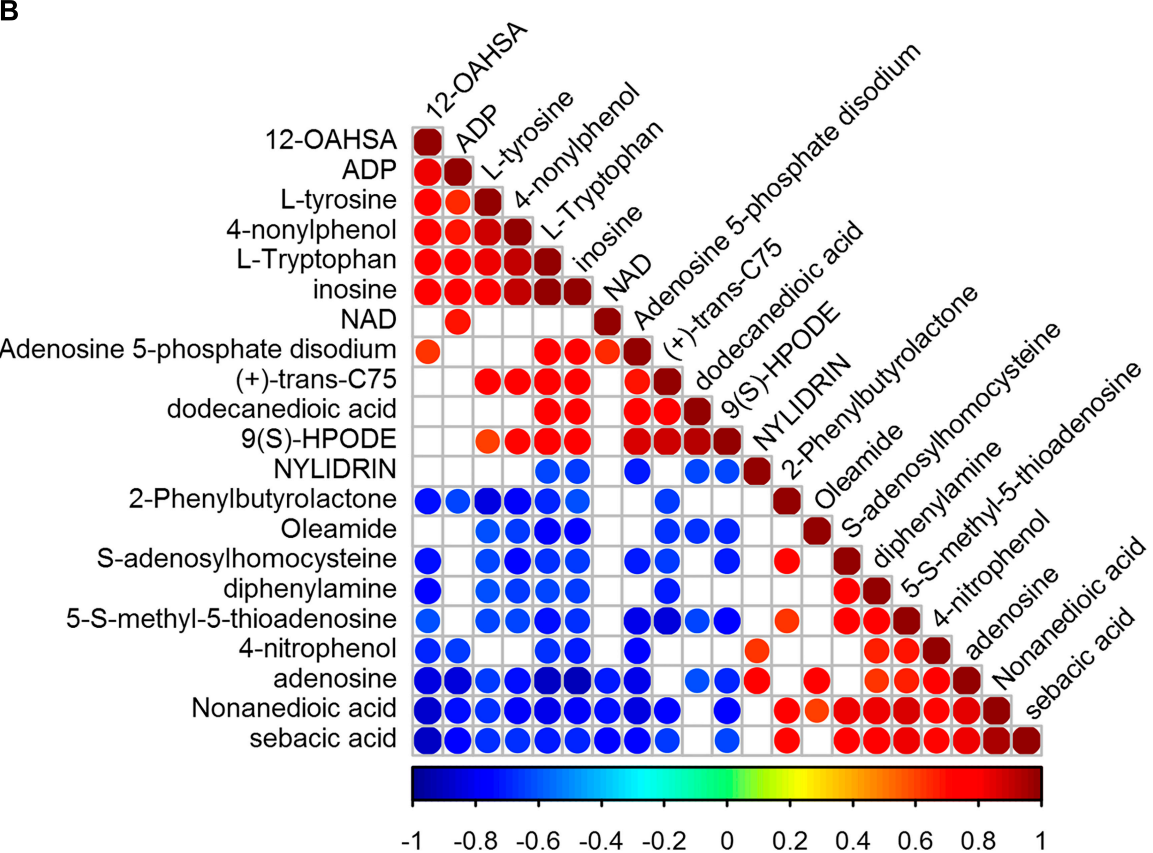

FIGURE $\mathbf{5}$ | Correlation of significantly variant metabolites of $B C G$ treated with $V_{B 1}$ (A) and BCG treated with $V_{C}$ (B) relative to control. Partial omics data of $V_{B 1}$ can be found in this published paper (Song et al., 2019).

least one gene encoding a key enzyme was down-regulated (Supplementary Table 10).

\section{$\mathbf{V}_{\mathrm{C}}$ Addition}

$\mathrm{V}_{\mathrm{C}}$ addition caused ornithine to increase 1.6-fold (Supplementary Table 9), consistent with a significant upregulation of genes involved in three out of five steps required to transform glutamate to ornithine (Supplementary Figure 6). Also, three out of four genes encoding enzymes that convert ornithine to arginine doubled their expression levels. $\mathrm{V}_{\mathrm{C}}$ addition also increased the content of aspartate 2.7-fold. L-asparaginase
[3.5.1.1], which converts Asn to Asp, increased 2-fold after $\mathrm{V}_{\mathrm{C}}$ addition (Supplementary Table 10). Thus, the observed increase of Thr might be due to an increase in Asp content (Supplementary Figure 6) and to a down-regulation of genes degrading Thr (Supplementary Table 10). The tryptophan synthase [4.2.1.20] gene was also significantly down-regulated (Supplementary Figure 6), consistent with the reduction of Trp in these conditions.

Strikingly, the cysteine synthase A [2.5.1.47] gene was significantly up-regulated in BCG treated with either $V_{B 1}$ or Vc (Supplementary Figures 5, 6). Finally, we found no 


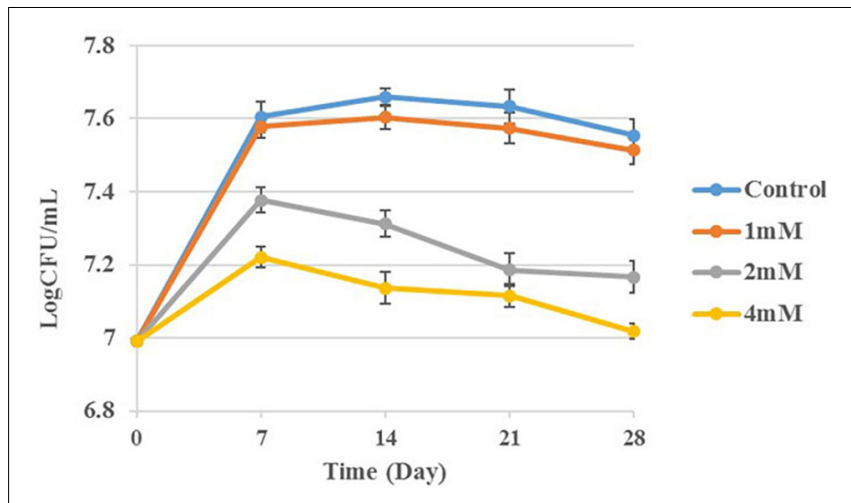

FIGURE 6 | BCG treatment with cysteine at concentrations 0, 1, 2, and $4 \mathrm{mM}$. Aliquots taken at indicated times and plated to determine CFUs.

direct association between base modification in coding or promoter regions and expression of genes involved in amino acid metabolism (Supplementary Table 10). Taken together, we found significant regulation of several genes directly involved in amino acid biosynthesis and metabolism, consistent with amino acid content changes. However, most gene expression changes were not significant. We speculate that treatment with $V_{B 1}$ and $V_{C}$ changes amino acid levels by altering precursor concentrations.

\section{Cysteine Inhibits BCG Growth}

Following the observation that vitamins treatment increase the transcription levels of cysteine synthase A, we determined the effect of cysteine on BCG replication. Different concentrations of cysteine $(0,1,2$, and $4 \mathrm{mM})$ were used for CFU calculation and the results are summarized in Figure 6. The growth curve demonstrates that cysteine inhibits BCG growth in a concentration-dependent manner.

\section{DISCUSSION}

Vitamins such as biotin and thiamine are essential for M. tuberculosis growth and infection (Tyagi et al., 2017), and Mtb scavenges these vitamins from the host. At the same time, supplementation of some vitamins together with anti-TB drugs has been shown to improve chemotherapy outcomes (Vilcheze et al., 2018). Clinical trials have shown that Vc supplementation improves the healing process in tuberculosis patients (Tjandrawinata et al., 2018), although no clinical improvement (sputum conversion) of patients was observed when using vitamin $\mathrm{D}\left(\mathrm{V}_{D}\right)$. Therefore, the mechanism by which some vitamins can ammeliorate TB requires further investigation.

Mtb growth is inhibited by vitamins $A\left(V_{A}\right)$ and $V_{D}$ (Greenstein et al., 2012, 2014), and recent studies have shown that $\mathrm{V}_{\mathrm{B} 1}$ and $\mathrm{Vc}$ also significantly inhibit BCG growth (Pei et al., 2019; Song et al., 2019). Thus, due to the potential supplementary role of certain vitamins in TB treatment, analysis of the BCG methylome can help elucidate the relationship between base methylation, gene expression and metabolic products.
Many DNA methylation enzymes are part of RM systems, and are involved in the defense against phages and viruses. We found $42.6 \%$ of BCG genes were m6A methylated, and these were enriched in key metabolism and cellular processes, hinting that essential genes in BCG are always protected by methylation.

Regulation of gene expression by DNA methylation occurs via more than one mechanism. DNA methylation hinders the interaction between DNA and regulatory proteins by direct atomic steric effects (Sanchez-Romero et al., 2015), or indirectly by altering DNA structure itself; this reduces the thermodynamic stability of the double helix, resulting in alteration of gene expression (Sanchez-Romero et al., 2015). Additionally, some DNA-binding proteins inhibit methylation of specific DNA sequences by binding to unmethylated DNA with high affinity.

In general, positive or negative transcription regulation depends on differences in the location of methylation sites in the promoter region, modulation of regulatory proteins, or differences in binding between regulatory proteins and unmethylated/methylated DNA target sequences. In the present study, we found that 138 genes $(64.8 \%)$ harboring $\mathrm{m} 4 \mathrm{C}$ in the coding region, and 11 genes harboring $\mathrm{m} 4 \mathrm{C}$ in the promoter region, were up-regulated in Vc-treated BCG. Additionally, 65 genes that harbored $\mathrm{m} 4 \mathrm{C}$ sites in the promoter region showed expression levels significantly higher than the control (no m4C sites), based on FPKM values. This suggests that $\mathrm{m} 4 \mathrm{C}$ can promote gene transcription to some extent, but using mechanisms that are still unknown. The m4C modification was observed in type I R-M systems, suggesting that, in addition to m6A modifications, they can also use this modification for host protection (Morgan et al., 2016).

Recent studies have shown that $\mathrm{N}^{4}$-cytosine DNA methylation can regulate transcription and pathogenesis in Helicobacter pylori (Kumar et al., 2018). Indeed, in human gastric adenocarcinoma cells, $H$. pylori mutant with increasing m4C methylation increased adhesion, while the bacteria without $\mathrm{m} 4 \mathrm{C}$ methyltransferase halved the adhesion rate and significantly reduced $H$. pylori-induced apoptosis. Additionally, in Cyanobacterium Synechocystis sp. PCC 6803m4C, methylation is involved in the regulation of gene expression, fine-tuning of DNA replication and DNA repair mechanisms (Gartner et al., 2019). Until now, however, the role of m4c modification in Mtb has been uncertain.

In our study, we found 11 up-regulated genes harboring an m4c modification in the promoter region (Supplementary Table 12) of BCG genome are homologous with these genes which had been studied to show important roles in Mtb. For example, Rv2416c (JTY_RS12525) is a secretory protein that enhances survival inside macrophages (Ganaie et al., 2011). Rv3130c (JTY_RS16210) encodes a triacylglycerol synthase that synthesizes triacylglycerol. This is proposed as an energy source during dormancy, and its disruption prevents triacylglycerol accumulation under inducing conditions (Sirakova et al., 2006). Rv2626c (JTY_RS13655) plays a significant role in macrophage pro-inflammatory response and in mycobacterial survival during infection (Sun et al., 2017). Rv0256c (JTY_RS01360), which can be used as a potential marker for the serodiagnosis of tuberculosis patients, may inhibit nitric oxide (NO) production in 
activated macrophages (Bhat et al., 2013; Abraham et al., 2014). Rv1187 (JTY_RS06330), encoding pyrroline-5-carboxylate dehydrogenase, was shown to be involved in the prolineutilization pathway in Mtb, and this pathway could be a valuable therapeutic target against TB (Jena et al., 2015). Additionally, Rv2308 (JTY_RS11970), Rv2100 (JTY_RS10875) and Rv2015c (JTY_RS10425) encoding hypothetical proteins, Rv2618 (JTY_RS13615) encoding transcription regulator, Rv2893 (JTY_RS14970) encoding oxidoreductase, Rv3892c (JTY_RS20265) encoding PPE protein are also methylated at the promoter region.

In metabolomics, we found that the concentrations of several metabolites including tryptophan, inosine, NAD and ADP decreased after $V_{B 1}$ and $V c$ treatment. Tryptophan is classified as an essential amino acid in humans and must be acquired through the diet. This requirement alleviates the concern of common targets within humans. Recent studies found that tryptophan synthase which catalyzes the final step in tryptophan biosynthesis is one potentially novel anti-tubercular drug target (Abrahams et al., 2017). In addition, treatment with 6-FABA 2-amino-6-fluoro-benzoic acid (6-FABA) chemically induces Mtb tryptophan auxotrophy. Together with immune- mediated trypothan starvation, this results in mycobacterial death. The results provide genetic and chemical validation of the tryptophan biosynthesis pathway as a target for highly active antibiotics (Zhang et al., 2013).

Inosine is made up of deaminizing adenosine and can be released extracellularly under inflammatory conditions (Jabs et al., 1995; Schmidt et al., 1995). Inosine has been reported to exert nutritional and neuroprotective functions in nerve cells, and stimulates mast cell degranulation by activating adenosine A3 receptor (Jin et al., 1997). Moreover, inosine exhibits antiinflammatory activity by inhibiting the release of inflammatory cytokine from activated $\mathrm{T}$ cells and promoting the formation of IL-10. Clinical trials have proposed that the use of inosine to raise serum urate levels may have benefits for at least some multiple sclerosis patients. The effect of this treatment is likely to be a consequence of inactivation of peroxynitrite-dependent free radicals (Markowitz et al., 2009).

$\mathrm{NAD}(\mathrm{P})$ is an indispensable cofactor for all organisms and its biosynthetic pathways are proposed as promising novel antibiotics targets against pathogens such as Mtb. It is reported that $\mathrm{NAD}(\mathrm{P})$ play the import role in immune response, gene silencing, DNA repair, regulation, redox reaction, energy and cellular metabolism which participate in more than 300 biochemical reactions, amounting to $17 \%$ of all the classical reaction (You, 1985; Bi et al., 2011). Nicotinamide adenine dinucleotide $(\mathrm{NAD}+)$ is essential for a variety of organisms, and it is both a coenzyme for hydride-transfer enzymes and a substrate for NAD+-consuming enzymes, such as ADPribose transferases, poly(ADP-ribose) polymerases, cADP-ribose synthases, and sirtuins.

Since the synthesis pathways of these significantly reduced metabolites are mostly drug targets for the treatment of tuberculosis, we hypothesized that the addition of vitamins may directly or indirectly affect the synthesis or metabolic processes of these products. This could potentially inhibit bacterial growth.
A striking result in this study is that $\mathrm{V}_{\mathrm{B} 1}$ treatment of BCG resulted in content reduction of almost all types of amino acids, whereas Vc treatment caused the opposite effect. Through RNA-seq analysis, we found that the gene encoding cysteine synthase A was significantly up-regulated after vitamin treatment, suggesting that Cys synthesis is promoted. It has been reported that isoniazid (INH)/Cys combination potentiates the killing of $\mathrm{Mtb}$ by stimulating respiration of $\mathrm{Mtb}$ from non-respiring dormancy (Vilcheze et al., 2017). High levels of intracellular cysteine can induce ROS production, causing DNA damage and oxidation of cysteine to cystine in E. coli (Park and Imlay, 2003). Indeed, transition metals, such as copper or iron, catalyze the oxidation of cysteine into cystine, leading to the production of hydrogen peroxide $\left(\mathrm{H}_{2} \mathrm{O}_{2}\right)$, superoxide, and hydroxyl radicals (Kachur et al., 1999). This high concentration of cysteine could therefore initiate cationic stress, resulting in the formation of ROS and DNA damage (Imlay et al., 1988; Demple and Harrison, 1994).

In our study, the gene encoding cysteine synthase $\mathrm{A}$ was significantly up-regulated after $\mathrm{V}_{\mathrm{B} 1}$ and $\mathrm{Vc}$ treatment and this hinting that the synthesis of cysteine is promoted. In addition, in vitro growth test show that cysteine inhibit the growth of BCG in a concentration-dependent manner. Therefore, we hypothesize that $V_{B 1}$ and $V c$ inhibit BCG growth by increasing the concentration of cysteine, which can eventually damage DNA via Fenton reaction. This hypothesis is consistent with the transcriptomics results, where Vc induced the expression of genes related to DNA repair, suggesting that Vc may indirectly affect DNA integrity.

Notably, the scientists found that Vc sterilized Mtb cultures via Fenton reaction and increased iron concentration, which correlates with the bactericidal activity of $\mathrm{V}_{\mathrm{C}}$ (Vilcheze et al., 2013). The results shown in the present study suggest that BCG growth inhibition may not be due just to high levels of iron, but also to cysteine. In addition, decreased concentrations of tryptophan, $\mathrm{NAD}(\mathrm{P})$ and other metabolites are also potential reasons for vitamin inhibition of BCG

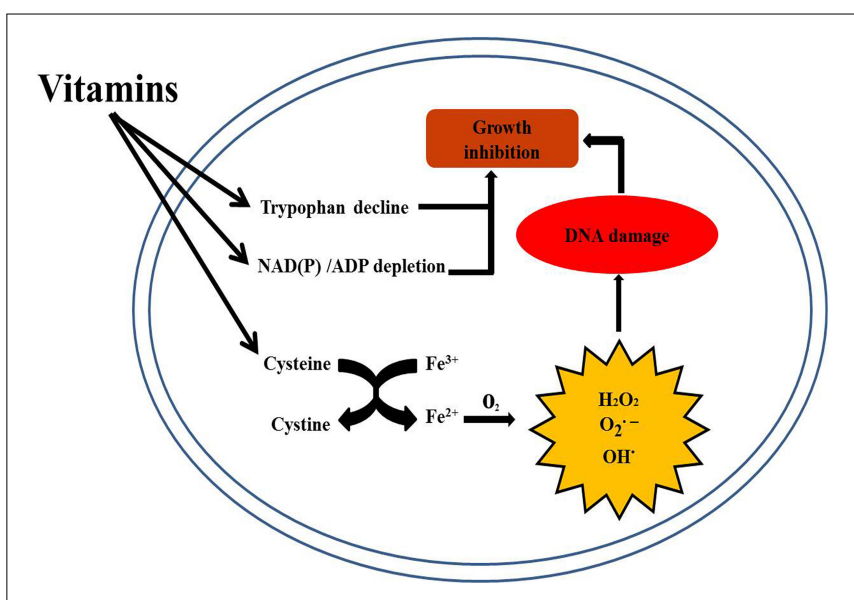

FIGURE 7 | Schematic representation of the mechanism of action of vitamins against BCG growth. 
growth (Figure 7). Our study also identifies another possible mechanism by which vitamins inhibit BCG growth. Therefore, $\mathrm{V}_{\mathrm{B} 1}$ and $\mathrm{Vc}$ supplementation may enhance the action of antituberculosis drugs.

\section{DATA AVAILABILITY STATEMENT}

The datasets generated for this study can be found in the Gene Expression Omnibus, accession numbers GSE114949 and GSE141513.

\section{AUTHOR CONTRIBUTIONS}

NS designed this study and wrote the manuscript. YZ analyzed the data and prepared the figures. YC, ML, YT, ZC, and GD participated in the data analysis. $\mathrm{HZ}$ participated in the data analysis and contributed to the writing. SL contributed to the

\section{REFERENCES}

Abraham, P. R., Latha, G. S., Valluri, V. L., and Mukhopadhyay, S. (2014). Mycobacterium tuberculosis PPE protein Rv0256c induces strong B cell response in tuberculosis patients. Infect. Genet. Evol. 22, 244-249. doi: 10.1016/ j.meegid.2013.06.023

Abrahams, K. A., Cox, J. A. G., Futterer, K., Rullas, J., Ortega-Muro, F., Loman, N. J., et al. (2017). Inhibiting mycobacterial tryptophan synthase by targeting the inter-subunit interface. Sci. Rep. 7:9430. doi: 10.1038/s41598-017-09642-y

Batra, S. D., Nandi, M., Sikri, K., and Tyagi, J. S. (2017). Genome-wide expression profiling establishes novel modulatory roles of vitamin C in THP-1 human monocytic cell line. BMC Genomics 18:252. doi: 10.1186/s12864-017-3635-4

Begley, T. P., Downs, D. M., Ealick, S. E., McLafferty, F. W., Van Loon, A. P. G. M., Taylor, S., et al. (1999). Thiamin biosynthesis in prokaryotes. Arch. Microbiol. 171, 293-300. doi: 10.1007/s002030050713

Betts, J. C., Lukey, P. T., Robb, L. C., McAdam, R. A., and Duncan, K. (2002). Evaluation of a nutrient starvation model of Mycobacterium tuberculosis persistence by gene and protein expression profiling. Mol. Microbiol. 43, 717731. doi: 10.1046/j.1365-2958.2002.02779.x

Bhat, K. H., Das, A., Srikantam, A., and Mukhopadhyay, S. (2013). PPE2 protein of Mycobacterium tuberculosis may inhibit nitric oxide in activated macrophages. Ann. N. Y. Acad. Sci. 1283, 97-101. doi: 10.1111/nyas.12070

$\mathrm{Bi}$, J., Wang, H., and Xie, J. (2011). Comparative genomics of NAD(P) biosynthesis and novel antibiotic drug targets. J. Cell. Physiol. 226, 331-340. doi: 10.1002/jcp. 22419

Blow, M. J., Clark, T. A., Daum, C. G., Deutschbauer, A. M., Fomenkov, A., Fries, R., et al. (2016). The epigenomic landscape of prokaryotes. PLoS Genet. 12:e1005854. doi: 10.1371/journal.pgen.1005854

Chen, J., Darst, S. A., and Thirumalai, D. (2010). Promoter melting triggered by bacterial RNA polymerase occurs in three steps. Proc. Natl. Acad. Sci. U.S.A. 107, 12523-11252. doi: 10.1073/pnas.1003533107

De Buck, J., Shaykhutdinov, R., Barkema, H. W., and Vogel, H. J. (2014). Metabolomic profiling in cattle experimentally infected with Mycobacterium avium subsp. paratuberculosis. PLoS One 9:e111872. doi: 10.1371/journal.pone. 0111872

Demple, B., and Harrison, L. (1994). Repair of oxidative damage to DNA: enzymology and biology. Annu. Rev. Biochem. 63, 915-948. doi: 10.1146/ annurev.bi.63.070194.004411

Dini, C., and Bianchi, A. (2012). The potential role of vitamin D for prevention and treatment of tuberculosis and infectious diseases. Ann. I Super Sanita 48, 319-327. doi: 10.4415/ANN_12_03_13

Fang, G., Munera, D., Friedman, D. I., Mandlik, A., Chao, M. C., Banerjee, O., et al. (2012). Genome-wide mapping of methylated adenine residues in pathogenic concepts and the writing. All authors have read and approved the final manuscript.

\section{FUNDING}

This work was supported by the National Natural Science Foundation of China (Grant Numbers 31873014, 31772767, and 31802188), the National Key R\&D Program of China (Grant Numbers 2017YFD0500906 and 2017YFD0500304), and Science Foundation of Heilongjiang Province (Grant Number QC2018034).

\section{SUPPLEMENTARY MATERIAL}

The Supplementary Material for this article can be found online at: https://www.frontiersin.org/articles/10.3389/fmicb. 2020.00812/full\#supplementary-material

Escherichia coli using single-molecule real-time sequencing. Nat. Biotechnol. 30:1232. doi: 10.1038/nbt.2432

Fisher, M. A., Plikaytis, B. B., and Shinnick, T. M. (2002). Microarray analysis of the Mycobacterium tuberculosis transcriptional response to the acidic conditions found in phagosomes. J. Bacteriol. 184, 4025-4032. doi: 10.1128/jb.184.14. 4025-4032.2002

Flusberg, B. A., Webster, D. R., Lee, J. H., Travers, K. J., Olivares, E. C., Clark, T. A., et al. (2010). Direct detection of DNA methylation during single-molecule, real-time sequencing. Nat. Methods 7, 461-U472. doi: 10.1038/nmeth.1459

Ganaie, A. A., Lella, R. K., Solanki, R., and Sharma, C. (2011). Thermostable Hexameric Form of Eis (Rv2416c) Protein of $M$. tuberculosis plays an important role for enhanced intracellular survival within macrophages. PLoS One 6:e27590. doi: 10.1371/journal.pone.0027590

Gartner, K., Klahn, S., Watanabe, S., Mikkat, S., Scholz, I., Hess, W. R., et al. (2019). Cytosine N4-Methylation via M.Ssp6803II is involved in the regulation of transcription, fine-tuning of DNA replication and DNA repair in the Cyanobacterium Synechocystis sp. PCC 6803. Front. Microbiol. 10:1233. doi: $10.3389 /$ fmicb. 2019.01233

Gibson, G. E., and Blass, J. P. (2007). Thiamine-dependent processes and treatment strategies in neurodegeneration. Antioxid. Redox Signal. 9, 1605-1619.

Greenstein, R. J., Su, L., and Brown, S. T. (2012). Vitamins A \& D inhibit the growth of mycobacteria in radiometric culture. PLoS One 7:e29631. doi: 10. 1371/journal.pone.0029631

Greenstein, R. J., Su, L., Shahidi, A., Brown, W. D., Clifford, A., and Brown, S. T. (2014). Unanticipated Mycobacterium tuberculosis complex culture inhibition by immune modulators, immune suppressants, a growth enhancer, and vitamins A and D: clinical implications. Int. J. Infect. Dis. 26, 37-43. doi: 10. 1016/j.ijid.2014.01.026

He, W. T., Hu, S. F., Du, X. L., Wen, Q., Zhong, X. P., Zhou, X. Y., et al. (2018). Vitamin B5 reduces bacterial growth via regulating innate immunity and adaptive immunity in mice infected with Mycobacterium tuberculosis. Front. Immunol. 9:365. doi: 10.3389/fimmu.2018.00365

Heyden, B., Nusslein, C., and Schaller, H. (1975). Initiation of transcription within an RNA-polymerase binding site. Eur. J. Biochem. 55, 147-155. doi: 10.1111/j. 1432-1033.1975.tb02147.x

Hu, S. F., He, W. T., Du, X. L., Huang, Y. L., Fu, Y. L., Yang, Y. L., et al. (2018). Vitamin B1 helps to limit Mycobacterium tuberculosis growth via regulating innate immunity in a peroxisome proliferator-activated receptorgamma-dependent manner. Front. Immunol. 9:1778. doi: 10.3389/fimmu.2018. 01778

Imlay, J. A., Chin, S. M., and Linn, S. (1988). Toxic DNA damage by hydrogen peroxide through the Fenton reaction in vivo and in vitro. Science 240, 640-642. doi: $10.1126 /$ science. 2834821 
Jabs, C. M., Neglen, P., and Eklof, B. (1995). Breakdown of adenine nucleotides, formation of oxygen free radicals, and early markers of cellular injury in endotoxic shock. Eur. J. Surg. 161, 147-155.

Jena, L., Deshmukh, S., Waghmare, P., Kumar, S., and Harinath, B. C. (2015). Study of mechanism of interaction of truncated isoniazid-nicotinamide adenine dinucleotide adduct against multiple enzymes of Mycobacterium tuberculosis by a computational approach. Inte. J. Mycobacteriol. 4, 276-283. doi: 10.1016/j. ijmyco.2015.06.006

Jin, X., Shepherd, R. K., Duling, B. R., and Linden, J. (1997). Inosine binds to A3 adenosine receptors and stimulates mast cell degranulation. J. Clin. Invest. 100, 2849-2857. doi: $10.1172 /$ jcil19833

Kachur, A. V., Koch, C. J., and Biaglow, J. E. (1999). Mechanism of coppercatalyzed autoxidation of cysteine. Free Radic. Res. 31, 23-34. doi: 10.1080/ 10715769900300571

Kim, J. K., Samaranayake, M., and Pradhan, S. (2009). Epigenetic mechanisms in mammals. Cell Mol. Life. Sci. 66, 596-612. doi: 10.1007/s00018-008-8432-4

Krebes, J., Morgan, R. D., Bunk, B., Sproer, C., Luong, K., Parusel, R., et al. (2014). The complex methylome of the human gastric pathogen Helicobacter pylori. Nucleic Acids Res. 42, 2415-2432. doi: 10.1093/nar/gkt1201

Kumar, S., Karmakar, B. C., Nagarajan, D., Mukhopadhyay, A. K., Morgan, R. D., and Rao, D. N. (2018). N4-cytosine DNA methylation regulates transcription and pathogenesis in Helicobacter pylori. Nucleic Acids Res. 46, 3815. doi: 10. 1093/nar/gky195

Langmead, B., and Salzberg, S. L. (2012). Fast gapped-read alignment with Bowtie 2. Nat. Methods 9, 357-U354. doi: 10.1038/nmeth.1923

Loots du, T. (2014). An altered Mycobacterium tuberculosis metabolome induced by katG mutations resulting in isoniazid resistance. Antimicrob. Agents Chemother. 58, 2144-2149. doi: 10.1128/AAC.02344-13

Luria, S. E., and Human, M. L. (1952). A nonhereditary, host-induced variation of bacterial viruses. J. Bacteriol. 64, 557-569. doi: 10.1128/jb.64.4.557-569.1952

Manzetti, S., Zhang, J., and van der Spoel, D. (2014). Thiamin function. metabolism, uptake, and transport. Biochemistry 53, 821-835. doi: 10.1021/ bi401618y

Markowitz, C. E., Spitsin, S., Zimmerman, V., Jacobs, D., Udupa, J. K., Hooper, D. C., et al. (2009). The treatment of multiple sclerosis with inosine. J. Altern. Complement. Med. 15, 619-625. doi: 10.1089/acm.2008.0513

Martini, M. C., Zhou, Y., Sung, H. M., and Shell, S. S. (2019). Defining the Transcriptional and Post-transcriptional landscapes of Mycobacterium smegmatis in aerobic growth and hypoxia. Front. Microbiol. 10:591. doi: 10. 3389/fmicb.2019.00591

Meissner-Roloff, R. J., Koekemoer, G., Warren, R. M., and Loots, D. T. (2012). A metabolomics investigation of a hyper- and hypo-virulent phenotype of Beijing lineage M-tuberculosis. Metabolomics 8, 1194-1203. doi: 10.1007/s11306-0120424-6

Mishra, A., and Sarkar, D. (2015). Qualitative and quantitative proteomic analysis of Vitamin C induced changes in Mycobacterium smegmatis. Front. Microbiol. 6:451. doi: 10.3389/fmicb.2015.00451

Moore, L. D., Le, T., and Fan, G. (2013). DNA methylation and its basic function. Neuropsychopharmacology 38, 23-38. doi: 10.1038/npp.2012.112

Morgan, R. D., Luyten, Y. A., Johnson, S. A., Clough, E. M., Clark, T. A., and Roberts, R. J. (2016). Novel m4C modification in type I restriction-modification systems. Nucleic Acids Res. 44, 9413-9425.

Murphy, J., Mahony, J., Ainsworth, S., Nauta, A., and van Sinderen, D. (2013). Bacteriophage Orphan DNA methyltransferases: insights from their bacterial origin. function, and occurrence. Appl. Environ. Microb. 79, 7547-7555. doi: 10.1128/AEM.02229-13

Parida, S. K., Axelsson-Robertson, R., Rao, M. V., Singh, N., Master, I., Lutckii, A., et al. (2015). Totally drug-resistant tuberculosis and adjunct therapies. J. Intern. Med. 277, 388-405. doi: 10.1111/joim.12264

Park, S., and Imlay, J. A. (2003). High levels of intracellular cysteine promote oxidative DNA damage by driving the fenton reaction. J. Bacteriol. 185, 19421950. doi: 10.1128/jb.185.6.1942-1950.2003

Pei, Z. L., Wu, K., Li, Z. H., Li, C. Q., Zeng, L., Li, F., et al. (2019). Pharmacologic ascorbate as a pro-drug for hydrogen peroxide release to kill mycobacteria. Biomed. Pharmacother. 109, 2119-2127. doi: 10.1016/j.biopha.2018.11.078

Pohl, M., Sprenger, G. A., and Muller, M. (2004). A new perspective on thiamine catalysis. Curr. Opin. Biotech. 15, 335-342. doi: 10.1016/j.copbio.2004.06.002
Reisenauer, A., Kahng, L. S., McCollum, S., and Shapiro, L. (1999). Bacterial DNA methylation: a cell cycle regulator? J. Bacteriol. 181, 5135-5139. doi: 10.1128/ jb.181.17.5135-5139.1999

Robinson, M. D., McCarthy, D. J., and Smyth, G. K. (2010). edgeR: a Bioconductor package for differential expression analysis of digital gene expression data. Bioinformatics 26, 139-140. doi: 10.1093/bioinformatics/btp616

Sanchez-Romero, M. A., Cota, I., and Casadesus, J. (2015). DNA methylation in bacteria: from the methyl group to the methylome. Curr. Opin. Microbiol. 25, 9-16. doi: 10.1016/j.mib.2015.03.004

Schmidt, H., Siems, W. G., Grune, T., and Grauel, E. L. (1995). Concentration of purine compounds in the cerebrospinal fluid of infants suffering from sepsis, convulsions and hydrocephalus. J. Perinat. Med. 23, 167-174. doi: 10.1515/ jpme.1995.23.3.167

Schnappinger, D., Ehrt, S., Voskuil, M. I., Liu, Y., Mangan, J. A., Monahan, I. M., et al. (2003). Transcriptional adaptation of Mycobacterium tuberculosis within macrophages: insights into the phagosomal environment. J. Exp. Med. 198, 693-704. doi: 10.1084/jem.20030846

Settembre, E., Begley, T. P., and Ealick, S. E. (2003). Structural biology of enzymes of the thiamin biosynthesis pathway. Curr. Opin. Struc. Biol. 13, 739-747. doi: 10.1016/j.sbi.2003.10.006

Shell, S. S., Prestwich, E. G., Baek, S. H., Shah, R. R., Sassetti, C. M., Dedon, P. C., et al. (2013). DNA Methylation Impacts Gene Expression and Ensures Hypoxic Survival of Mycobacterium tuberculosis. PLoS Pathog. 9:e1003419. doi: 10.1371/journal.ppat.1003419

Shiloh, M. U., Manzanillo, P., and Cox, J. S. (2008). Mycobacterium tuberculosis senses host-derived carbon monoxide during macrophage infection. Cell Host Microbe 3, 323-330. doi: 10.1016/j.chom.2008.03.007

Sirakova, T. D., Dubey, V. S., Deb, C., Daniel, J., Korotkova, T. A., Abomoelak, B., et al. (2006). Identification of a diacylglycerol acyltransferase gene involved in accumulation of triacylglycerol in Mycobacterium tuberculosis under stress. Microbiol. Sgm 152, 2717-2725. doi: 10.1099/mic.0.28993-0

Song, N., Li, Z., Cui, Z., Chen, L., Cui, Y., Dang, G., et al. (2019). The prominent alteration in transcriptome and metabolome of Mycobacterium bovis BCG str. Tokyo 172 induced by vitamin B1. BMC Microbiol. 19:104. doi: 10.1186/s12866019-1492-9

Sun, C. F., Yang, G. P., Yuan, J. N., Peng, X., Zhang, C. X., Zhai, X. Q., et al. (2017). Mycobacterium tuberculosis hypoxic response protein 1 (Hrp1) augments the pro-inflammatory response and enhances the survival of Mycobacterium smegmatis in murine macrophages. J. Med. Microbiol. 66, 1033-1044. doi: 10.1099/jmm.0.000511

Swanepoel, C. C., and Loots, D. (2014). The use of functional genomics in conjunction with metabolomics for Mycobacterium tuberculosis research. Dis. Markers 2014:124218. doi: 10.1155/2014/124218

Syal, K., Chakraborty, S., Bhattacharyya, R., and Banerjee, D. (2015). Combined inhalation and oral supplementation of Vitamin A and Vitamin D: a possible prevention and therapy for tuberculosis. Med. Hypotheses 84, 199-203. doi: 10.1016/j.mehy.2014.12.022

Tjandrawinata, R. R., Setiawati, A., Nofiarny, D., Susanto, L. W., and Setiawati, E. (2018). Pharmacokinetic equivalence study of nonsteroidal anti-inflammatory drug etoricoxib. Clin. Pharmacol. 10, 43-51. doi: 10.2147/CPAA.S16 1024

Tyagi, G., Singh, P., Varma-Basil, M., and Bose, M. (2017). Role of Vitamins B, $\mathrm{C}$, and D in the fight against tuberculosis. Int. J. Mycobacteriol. 6, 328-332. doi: 10.4103/ijmy.ijmy_80_17

Vilcheze, C., Hartman, T., Weinrick, B., and Jacobs, W. R. (2013). Mycobacterium tuberculosis is extraordinarily sensitive to killing by a vitamin C-induced Fenton reaction. Nat. Commun. 4:2898. doi: 10.1038/ncomms2898

Vilcheze, C., Hartman, T., Weinrick, B., Jain, P., Weisbrod, T. R., Leung, L. W., et al. (2017). Enhanced respiration prevents drug tolerance and drug resistance in Mycobacterium tuberculosis. Proc. Natl. Acad. Sci. U.S.A. 114, 4495-4500. doi: $10.1073 /$ pnas. 1704376114

Vilcheze, C., Kim, J., and Jacobs, W. R. Jr. (2018). Vitamin C potentiates the killing of Mycobacterium tuberculosis by the first-line tuberculosis drugs isoniazid and rifampin in mice. Antimicrob. Agents Chemother. 62:AAC.02165-17. doi: 10.1128/AAC.02165- 17

World Health Organization [WHO] (2019). Global Tuberculosis Report. Geneva: WHO. 
Yang, X. J., Han, H., De Carvalho, D. D., Lay, F. D., Jones, P. A., and Liang, G. N. (2014). Gene body methylation can alter gene expression and is a therapeutic target in cancer. Cancer Cell 26, 577-590. doi: 10.1016/j.ccr.2014. 07.028

You, K. S. (1985). Stereospecificity for nicotinamide nucleotides in enzymatic and chemical hydride transfer reactions. CRC Crit. Rev. Biochem. 17, 313-451. doi: 10.3109/10409238509113625

Zhang, Y. J., Reddy, M. C., Ioerger, T. R., Rothchild, A. C., Dartois, V., Schuster, B. M., et al. (2013). Tryptophan biosynthesis protects mycobacteria from CD4 T-cell-mediated killing. Cell 155, 1296-1308. doi: 10.1016/j.cell.2013. 10.045

Zhu, L. X., Zhong, J., Jia, X. M., Liu, G., Kang, Y., Dong, M. X., et al. (2016). Precision methylome characterization of Mycobacterium tuberculosis complex (MTBC) using PacBio single-molecule real-time
(SMRT) technology. Nucleic Acids Res. 44, 730-743. doi: 10.1093/nar/gkv 1498

Conflict of Interest: The authors declare that the research was conducted in the absence of any commercial or financial relationships that could be construed as a potential conflict of interest.

Copyright (C) 2020 Song, Zhu, Cui, Lv, Tang, Cui, Dang, Zheng and Liu. This is an open-access article distributed under the terms of the Creative Commons Attribution License (CC BY). The use, distribution or reproduction in other forums is permitted, provided the original author(s) and the copyright owner(s) are credited and that the original publication in this journal is cited, in accordance with accepted academic practice. No use, distribution or reproduction is permitted which does not comply with these terms. 